\title{
Freire's Time: Unlocking Energy and Options for Out-of-School Youth in Jordan
}

\author{
Elizabeth Robinson \\ Questscope \\ Curt Rhodes \\ Questscope
}

\begin{abstract}
Introduction: This is Freire Time
One afternoon in March 2020, the Jordanian Ministry of Education (MoE) announced the immediate, indefinite closure of all schools in the country to prevent the spread of COVID19. This affected 2.7 million children and youth (UNESCO, 2017), including 3,000 youth in a non-formal education (NFE) program jointly operated by the MoE and Questscope, a non-governmental organization (NGO) focused on youth on the periphery of society.
\end{abstract}

Within a month, $75 \%$ of these NFE youth (2,400 teenagers!) had contacted each other and their educational facilitators (teachers) through WhatsApp and Facebook to organize lessons and conversations with friends and family. Among students in formal school nationwide, only $54 \%$ had access to (though even fewer likely attended) online classes (UNHRC et al., 2020). This contrast between NFE and formal school learners made a lasting impression on educators, as it reflected youths' desire to reconnect with their peers and facilitators.

This eagerness-this drive to stay in a learning community-is a direct result of integrating the seminal approaches of Brazilian educationalist Paulo Freire into Jordan's NFE program. NFE supports individuals' right to make their own choices and learn how to make increasingly better-informed choices-to think critically. The teacher's role as an educational facilitator, and their resulting mentoring relationship with students, lays a critical and hopeful foundation for out-of-school (OOS) youth learners to negotiate the uncertainties of life-a challenge for which they would otherwise be unprepared and unsupported. In this way, the pedagogical approach of Freire unlocks the energy of voluntary learning (learners are there because they want to be, not because they have to be) among OOS youth to explore, examine and create.

This is Freire time. In the wake of the pandemic - which affected 1.6 billion children around the world-there has never been a more critical time to apply his pedagogy of hope. Fostering a culture of learning with teachers as cultural workers, and making a path for them to walk alongside students, is a vital solution to the dysfunction of youth education and the social disconnection of these COVID-influenced days. It is a solution that can cultivate hope for those at the margins, whom the pandemic pushed even farther towards the edge, as well as those who accompany them.

Freirean pedagogies enable two especially important outcomes to ready young people for the emerging world that cannot be "blueprinted" in advance:

- Critical thinking about responsibility for oneself and understanding how to succeed in the world in which one finds oneself, i.e., self-efficacy. 
- Critical consciousness, in which one is aware of what needs to be/can be changed in the system in which one must succeed in order to make things "better."

The following sections will explore how these approaches have been utilized as part of the NFE program in Jordan.

\section{Letting Go of Legacy Education Systems}

The Questscope/MoE NFE program is certified by the MoE and enables 13-18 year-olds to complete the academic requirements for $10^{\text {th }}$ grade within 24 months. NFE is tailored to OOS youth, including drop-outs and refugees, who do not have or cannot access other forms of education, including formal education. The curriculum for NFE is designed based on the public school curriculum in Jordan and is implemented through teaching pedagogies influenced by the ideas of Freire and adapted to the Jordan context. The approach of Freire, practiced in NFE, offers remarkable opportunities for children and youth to learn and secure the benefits of education that open doors that lead up and out.

The Freirean model of NFE is unique because it provides certification for basic education, which, in Jordan, is required for students to progress academically, vocationally / technically, or to secure regular employment. Such certification was not an initial concern of Freire, given his focus on adult education. However, his participatory learning approach has been very successful for young people in NFE who need certification but cannot get it from a formal system.

NFE is organized around learners, to whom Questscope and the MoE are accountable, and who voluntarily enroll-and stay-in NFE. When a young person leaves formal education, they have a choice of what to pursue next, and they look for the best option available. NGOs such as Questscope must satisfy these youth, or else they-as volunteer learners-will leave the NFE program and find other opportunities, some of which will likely have negative outcomes. Young people are satisfied-and will stay-if learning is safe, appealing, and has an "off-ramp" leading to someplace they want to go. If not, they will leave-and cannot be required to return.

NFE is highly suitable for three types of learners. First, youth who dropped out of school after negative experiences in education because of bullying, intimidation, physical harm, or humiliation. Second, refugee youth who found themselves suddenly cut off from their homes, lives, communities, and friends and faced unsafe and unsupportive educational and social environments. And third, young people disconnected by COVID-imposed social isolation.

Educating OOS children and youth is both a global issue and a local issue in Jordan. In 2018, 258 million young people worldwide were not in school (UNESCO, 2020). In Jordan, over 112,000 young people were OOS (35\% Jordanian and 65\% other nationalities), and an additional 40,000 were at an increased risk of dropping out (UNICEF, 2020). These figures have likely increased since COVID-19.

While the pandemic may be unprecedented in terms of the number of young people globally who have had their schooling disrupted, the phenomenon of losing months or years of education is not a new experience for vulnerable youth. Young people in lowresource contexts constantly face competing priorities, opportunity costs, and decisions vis-à-vis how to best prepare themselves for the future they want. 
COVID has added yet another disruptive factor to this ongoing negotiation and balancing act. In the absence of (formal) education, young people have found, and will continue to find, other alternatives that best serve their ever-shifting needs and aspirations. In this emerging post-COVID era, it is a good time for educators to consider new questions about the ambitions of youth themselves. This is Freire time.

Legacy-that is, established-education systems equate time spent in formal school ("schooling") with learning, which is often not the case (Pritchett, 2013). The Learning Adjusted Years of Schooling (LAYS) measure, developed by the World Bank, indicates that the average Jordanian spends 11 years in school but receives less than seven years of quality education during that time (Filmer et al., 2018). Four (almost 40\%) of the years a young person spends in school are not productive for learning, and that "lost" time has a high opportunity cost. Youth who live on the economic and social margins have complex strategies for survival that do not include spending $40 \%$ of their effort on unproductive activities that do not lead to any goal.

\section{A New Educational Theory of Change}

NFE's theory of change is based on three key elements: adult-youth partnerships, dialectic (not didactic) learning, and youth agency. First, learning occurs in the context of an authentic, nurturing partnership between the youth learner and the adult facilitator. The learner trusts the facilitator to accompany them through an immersive inquiry of their own experiences, and the facilitator allows the learner to determine the course and content of their own explorations. These adult-youth partnerships create an atmosphere of trust, care, and belonging in the classroom that is essential to learning.

Second, NFE learners engage in a critical reflection of their lived experiences through a classroom dialogue with their facilitator and peers. Content learning is based on dialogue shaped around daily encounters and complexities that texture and inform the reality of all young people; the facilitator cultivates curiosity in these experiences.

Third, youth get opportunities to take initiative and exercise self-direction (agency) in what and how they learn. For example, the first assignment for every new NFE class is to create a "class constitution," which sets rules for behavior within the class. Learners in one NFE class decided that smoking was not allowed, so when an inspector came to the class and lit up, a student politely informed him that smoking was not permitted - a corrective action that would have been unheard of in a formal classroom context.

The application of Freirean principles in this theory of change has led to a new genre of educational facilitators who co-learn alongside students. The legacy system of education in Jordan has a wealth of human resource potential in the form of teachers' extensive content knowledge, which has greatly benefitted NFE. Educational facilitators engage in an 80-100-hour ongoing program of formation (training) in Questscope's participatory learning methodology, which includes an initial session followed by refresher trainings every four months. Self-directed professional development through Communities of Practice also provides facilitators with continuing education in Freirean philosophy and practice.

As part of the NFE program, learners also engage in extracurricular activities that range from trips to museums to STEM activities. Community outreach volunteers help to broaden the interest and support of the parents/community around youth, and alliances 
are built with youths' employers (for those who abide by International Labor Organization guidelines for safe work) to support education that is mutually beneficial for both the youth and the employer.

In 2010, Questscope and the MoE partnered with the University of Oxford to conduct a randomized controlled trial to evaluate the impact of NFE. The program was found to reduce conduct problems and violent behavior among youth within four months. Youth had statistically significantly improved outcomes related to prosocial behavior, overall difficulties, and hyperactivity/attention. The study also revealed encouraging changes in social and emotional outcomes in youth who had higher levels of attendance and those in NFE centers that offered more initiatives to empower youth in their learning progress. Significantly reducing violent behavior is critical for youth, as learning is almost impossible in an atmosphere where they fear for their personal safety (University of Oxford, 2011).

\section{Conclusion}

Educational preparation for the future is no longer an exercise in linear projection within a known context, and formal systems of education are often faulted for not preparing young people for the world in which they must succeed. The NFE program in Jordan has shown that the pedagogies of Paulo Freire can prepare learners for this unknowable future by cultivating the personal assets of critical thinking and critical consciousness. The educational facilitator - the adult partner - has a key role in generating the social and emotional connection and belonging that is critical to sustain Freire's approach. Going forward, this practice of educational mentoring can be combined with technology to scale up both access to education and the quality of learning experiences.

Curt Rhodes is the Founder/International Director of Questscope, which has partnered with marginalized communities in the Middle East since 1988 to strengthen communities. Dr. Rhodes holds an MPH from the University of North Carolina at Chapel Hill and MS and PhD degrees from the University of Wisconsin, Madison. Email: curt.rhodes@questscope.org

Elizabeth Robinson is a Researcher at Questscope and an independent consultant specializing in promoting education in low-resource contexts. After working in the Global South for six years, Elizabeth is now pursuing a Master's degree in Education and International Development at University College London. She also holds a BA from Tufts University.

Email: erobinson100@gmail.com 


\section{References}

Filmer, D. P., Rogers, F. H., Angrist, N., \& Sabarwal, S. (2018, September 27). Learningadjusted years of schooling (LAYS): Defining a new macro measure of education. World Bank Group.

http: / / documents.worldbank.org/ curated/en/243261538075151093/LearningAdjusted-Years-of-Schooling-LAYS-Defining-A-New-Macro-Measure-ofEducation

Pritchett, L. (2013). The rebirth of education: Schooling ain't learning. Center for Global Development.

UNESCO UIS. (2017). Jordan. http:/ / uis.unesco.org/en/ country/jo

UNESCO UIS. (2020). Out-of-school children and youth. http: / / uis.unesco.org/en/topic/ out-school-children-and-youth

UNHCR, UNICEF, WFP. (2020). Multi-sectoral rapid needs assessment: COVID19 - Jordan. https: / / www.unicef.org/jordan/media/2441/ file/RAN.pdf

UNICEF. (2020). Jordan country report on out-of-school children. https: / / www.unicef.org/jordan/media/5501/ file/OSC-Report-EN.pdf

University of Oxford, Questscope, Jordan Ministry of Education (2011). Strengthening youth opportunities: A pilot impact and process study of empowerment-based non-formal education for out-of-school youth in Amman, Jordan. 